\title{
Colima a finales del siglo XVIII
}

\author{
Jaime Olveda \\ EL COLEGIO DE JALISCO
}

LA LABOR Reorganizativa de PÉRfZ PONCE DE LEON

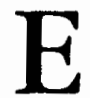

n mayor o menor medida, las regiones de la América española experimentaron importantes transformaciones a partir del reinado de Carlos III como consecuencia de la aplicación de un conjunto de disposiciones políticas, administrativas y eco. nómicas que estaban orientadas a impulsar la economía peninsular. En efecto, los Borbones se distinguieron por tratar de implantar una administración que fuera capaz de obtener un mayor excedente de las colonias americanas para poder subsidiar el desarrollo de la península.

Diversos estudios han explicado el impacto que tuvieron las reformas borbónicas en algunas regiones america- nas. Ahora se dispone, por ejemplo, de una amplia información acerca del desarrollo urbano que alcanzaron las ciudades, del incremento de la población, del aumento registrado en las distintas ramas de la producción y de la ampliación que experimentaron los circuitos comerciales. Pero ante todo fue la explotación minera, que requirió de cantidades mayores de productos para abastecer las necesidades de los mineros, la que impulsó y vigorizó directa o indirectamente la economía de muchas localidades. Hay coincidencia entre los historiadores que estudian la última parte del periodo colonial en el sentido de que el auge de la producción argentífera y la práctica del libre comercio propiciaron el florecimiento de varias regiones y ciudades.

Como se ha dicho, el impacto del reformismo borbónico no fue unifor- 
me. Por lo que respecta a Nueva España, fue esencialmente la zona centro oeste, o sea la que ya estaba plenamente integrada al mercado mundial a través de la minería, en donde se observan las mayores repercusiones. En cambio, en otras regiones como el nor. te o el sur, los alcances fueron menos estrepitosos.

El caso de Colima reviste peculiaridades específicas debido a su posición geográfica y a su condición política. Incorporada al virreinato novohispano desde el siglo XVI, había permanecido muy al margen del movimiento político y económico que se gestaba en la ciudad de México, dando la impresión de que se trataba simple y sencillamen. te de un apéndice de ese inmenso territorio. Es más, su lejanía respecto a la capital política y la dificultad de mantener una constante comunicación con el virrey y la Audiencia, propiciaron que la mayor parte de los problemas locales se mantuvieran sin resolver. Los colimenses, por su parte, al sentirse desamparados fueron albergando un sentimiento de frustración y nostalgia, que era justamente fomentado por esa enorme distancia que los separaba del centro político y por la desilusion que muchos experimentaron al no haber encontrado la riqueza minera que la mayoría de los colonos había imaginado.

A hora bien, el trayecto que había de por medio entre Colima y la ciudad de México, contrastaba con la cercanía que había con Guadalajara. Con el tiempo la proximidad con esta ciudad permitió que ésta fuera ejerciendo una poderosa influencia política y económica sobre Colima, de tal suerte que poco a poco los empresarios tapatíos empezaron a invertir considerables sumas de dinero en el mercado urbano colimense. Bajo estas circunstancias, los beneficios que estaba redituando el libre comercio en algunas regiones no favorecieron a Colima, en primerlugar por la escasez de productos que generaba la zona y la lejanía que la separaba de otros centros de consumo y, en segundo término, por el peso que empezó a ejercer Guadalajara.

Ese aislamiento de más de dos siglos y la poca atención que tuvieron los virreyes hacia Colima, engendraron tal desorganización que ya para el último cuarto del siglo XVIII había adquirido matices muy peligrosos. Para tratar de enderezar el estado deplorable en que se encontraban las cuestiones políticas y administrativas, el rey nombró en 1772 como alcalde mayor de Colima, a Miguel José Pérez Ponce de León. ${ }^{1}$ Este funcionario recibió, entre otras instrucciones, la de realizar una investigación sobre las tierras y salinas del Real Patrimonio, que varios hacendados de la región se habían adjudicado ilegalmente, y la de abocarse a solucionar otros aspectos de la problemática local que patentizaban el desorden prevaleciente.

Una de las primeras irregularidades que observó Ponce de León fue, ciertamente, la tendencia de los poderosos propietarios de Zapotlán el Grande de adjudicarse las tierras realengas de la jurisdicción colimense. Hasta la llegada de este funcionario, estos hacendados no habían encontrado obstáculo alguno para apropiarse de esos terre-

1 Pérez, "Estudio", 1979, p. 171. 
nos, ya que la distancia que los separaba de la cabecera política alejaba la posibilidad de que se les emprendiera algún juicio al respecto. La misión fiscalizadora de Pérez Ponce de León incomodó igualmente a los propietarios colimenses, que también habían incorporado a sus latifundios algunas salinas y tierras pertenecientes a la corona española.

Como el alcalde mayor actuó con rigor para sujetar a los poderosos y no aceptó sobornos ni formar alianzas con ninguno de los grupos, fue objeto de varios atentados. En estas circunstancias le resultó peligroso vivir en la villa de Colima, razón por la cual decidió fundar, en la primavera de 1776 , el pueblo de Nuestra Señora de Guadalupe de Tecalitlán, para fijar allí su residencia. Con el establecimiento de esta población pudo, además, congregar a los indígenas que vivían dispersos en una extensión de 25 leguas a la redonda. Para afianzar la fundación de este poblado e imponer su autoridad en toda la región, Pérez Ponce de León creó un cuerpo miliciano integrado por 50 lanceros a caballo. ${ }^{2}$

Otro de los aspectos en los que se percibía un grave desconcierto era en el ramo fiscal, ya que la recaudación se llevaba a cabo con muchas irregularidades. En 1778 fue necesario que Pérez Ponce de León utilizara a sus lanceros para poder cobrar las alcabalas. Como los asuntos religiosos estaban igual. mente desatendidos, hizo las gestiones pertinentes para que el obispo de Va. lladolid, Luis Fernando de Hoyos, en-

2 Ibtd. viara a Colima a un grupo de religiosos para que cubriera las necesidades espirituales de los indígenas. No menos importante fue su esfuerzo por reglamentar y hacer operativo el suministro de productos básicos a la villa, lo cual im. plicó enfrentarse con los abastecedo. res que ejercían el monopolio. Como éstos tenían en sus manos los puestos del Ayuntamiento, el alcalde mayor tuvo que vencer muchos obstáculos para imponerse. 3

La reorganización que llevó a cabo Pérez Ponce de León provocó el disgusto de quienes integraban el grupo de poder local. Él mismo llegó a informar al virrey, una vez concluida su misión, haber sido objeto de varias conjuras y atentados. ${ }^{4}$ Para comprender mejor el papel que desempeñó este funcionario, hay que tener presente que su designación tuvo lugar precisamente en el momento en que la corona había decidido recuperar el control de sus dominios americanos mediante una eficaz administración y la designación de individuos capaces de llevar a cabo esta empresa. Pérez Ponce de León fue un gobernante ilustrado que trató de cumplir al pie de la letra los desig. nios del Estado al que representaba.

Por lo que respecta a la villa de Colima, la imagen que proporciona Pérez Ponce de León entre 1776 y 1777 , es la de una población de escasa importancia y mal organizada políticamente. Según su informe, la mayor parte de los

3 Ibid., p. 172.

4 Una vez terminada su gestión, continuó siendo comandante de las milicias de Colima, dedicándose además a la explotación de las minas que descubrió en las serranías de Tecalitlán. Ibid. 
oficios del cabildo civil estaban vacantes, pues sólo dos regidores, "uno sin título y otro en arrendamiento", integraban el Ayuntamiento. La impunidad prevaleciente había dado lugar a que se entronizara un régimen de crimen sin castigo, mismo que toleraba una sociedad propensa a la corrupción, al vicio y al libertinaje. Al parecer, los alcaldes mayores anteriores a Pérez Ponce de León, que trataron de enderezar la situación, vieron destruir su carrera política por las numerosas infamias y calumnias que algunos colimenses les atribuyeron con el fin de que fueran destituidos. Por consiguiente, no hubo un solo funcionario que se hubiera vanagloriado de haber concluido felizmente su periodo. Por toda esta corruptela, a Pérez Ponce de León le parecía imposible que en una jurisdicción tan pequeña predominara "tanta maldad". 5

Igual desconcierto privaba en el comercio. Cuatro o seis mercaderes eran los que controlaban la circulación de las mercancías, las cuales introducían sin cubrir el pago de los impuestos correspondientes. El poder de estos comerciantes era casi absoluto porque, incluso poco antes del arribo de Pérez Ponce de León a la villa, habían obtenido por 3100 pesos, en remate público, el derecho de cobrar las alcabalas. Tal prerrogativa les permitió someter tanto a los pequeños productores de sal, coco y algodón, como a los escasos comerciantes viandantes que arribaban a la villa. ${ }^{6}$

\footnotetext{
5 "Descripción", 1979, p. 190.

6 Ibid., p. 188.
}

\section{EL ESCASO DESARROLLO ECONÓMICO}

En el último cuarto del siglo XVIII, Colima se integró un poco más a la economía novohispana a través de la producción y venta de la sal. ${ }^{7}$ La demanda de este producto fue cubierta casi exclusivamente por las fuentes salitreras de Cuyutlán, propiedad de Pedro Romero de Terreros, conde de Regla. ${ }^{8}$

Al auge minero se debe que la explotación de la sal cobrara mucha importancia. Según los informes rendidos por Pérez Ponce de León, la sal extraí. da de Colima en el último cuarto del siglo XVIII rebasaba las 30000 cargas anuales. ${ }^{9}$ En vista de las enormes ganancias que dejaba la comercialización de este producto, los bancos de sal pronto empezaron a ser motivo de disputas. En 1790 el Ayuntamiento de Colima inició un litigio para apropiarse de los terrenos y salitrales de la hacien. da de Cuyutlán, no obstante que el conde de Regla poseía certificados legítimos que lo reconocían como auténtico propietario. ${ }^{10}$ En ese tiempo el cabildo no obtuvo resultados favorables, pero volvería a insistir en sus pretensiones en el siglo siguiente.

Por otro lado, los poderosos comerciantes de Guadalajara, siempre al acecho de los buenos negocios, hicieron

7 Desde principios del siglo xvil ya había varios peninsulares dedicados a la explotación de este producto. Uno de ellos fue el bachiller Juan de Grijalva. Madrid Castro, "Colima Colonial", 1978 , p. 42.

8 Brading, "Mineros", 1975, p. 358.

9 "Descripción", 1979, p. 188.

10 Biblioteca Pública del Estado de Jalisco (BPE), Miscelánea 633, Consulta que el..., 1868, pp. 829. 


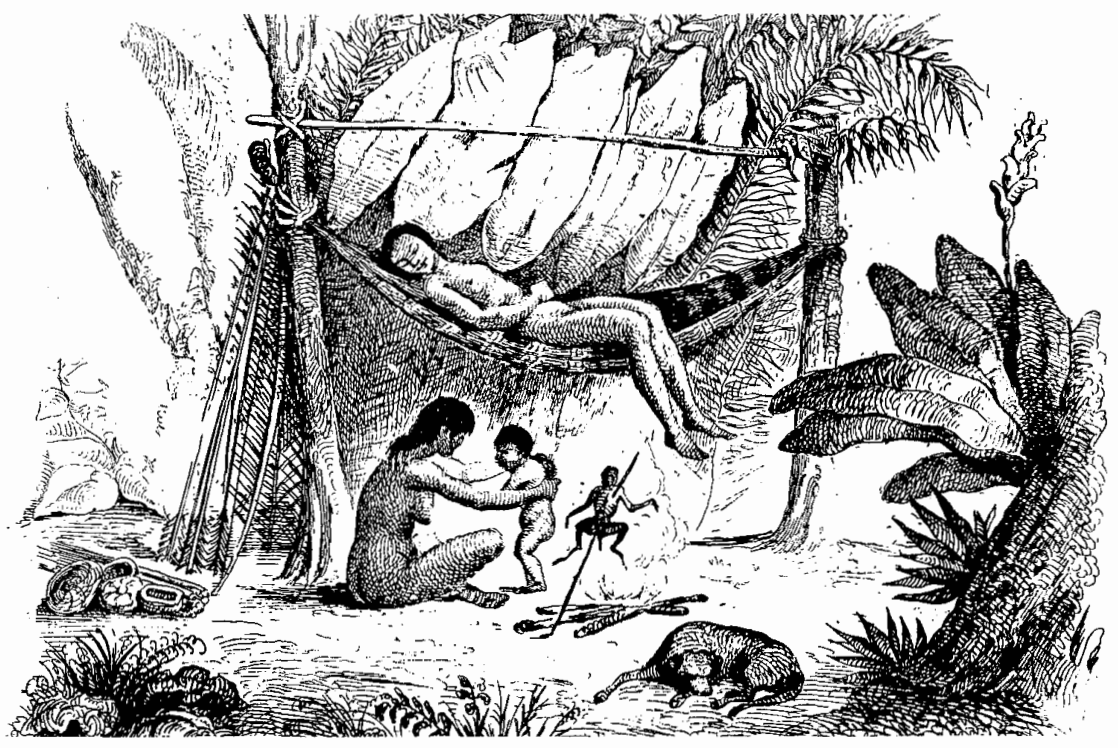

más de un intento para comercializar la sal de Colima. En 1804 llegaron al grado de comprar toda la producción de las salinas con el propósito de ser ellos quienes la distribuyeran a los mineros de Guanajuato y Zacatecas. ${ }^{11}$

Aparte de la sal, otros productos que se exportaban de Colima para Guadalajara, Sayula, Compostela y Guanajuato, eran el coco, ${ }^{12}$ el arroz, el

11 Véase Brading, Mineros, 1975, p. 358.

12 Aquí vale la pena comentar que los colimenses consiguieron, el 4 de marzo de 1627 , que el virrey de Nueva España les concediera la primera licencia para producir vino de coco y venderlo libremente en el territorio novohispano durante un periodo de diez años; $e l 11$ de febrero de 1637 obtuvieron el mismo privilegio por el término de ocho años; el 15 de diciembre de 1644 se les concedió otro permiso por diez años; chicle, las maderas, las hortalizas y algunas frutas propias de las regiones cálidas y húmedas, entre ellas el limón. ${ }^{13} \mathrm{Al}$ auge notable que tuvieron los talleres textiles de Guadalajara, y los de otras poblaciones como Sayula,

el 19 de abril de 1653 otro más por un decenio; el 31 de octubre de 1664 la autorización fue tan sólo por cuatro años; finalmente, el 15 de mayo de 1668 se otorgó otra licencia por seis años. El 19 de enero de 1672, la Audiencia de Guadalajara basándose en el dictamen que había emitido el Protomedicato de la Nueva España en el sentido de que el vino de coco no era nocivo para la salud -razón por la cual concedió los permisos anteriores- y en atención a la solicitud que presentó Juan de Ballesteros a nombre del cabildo de Colima, dio su anuencia para que dicha bebida se vendiera en la jurisdicción neogallega. Archivo de Instrumentos Públicos de Jalisco (AIPJ), Libro de Gobierno, tomo 1 , fojas $180 \mathrm{v} 184 \mathrm{f}$. L.

13 "General noticia", 1973 p. 31 
se debe el hecho de que se haya extendido con asombrosa rapidez el cultivo del algodón, de la grana y del añil en algunas partes de Colima. Cuando esto ocurrió, el Real Consulado de Guadalajara se interesó en mantener en buen estado la ruta que unía a la capital neogallega con la región colimense, con el propósito de facilitar el traslado de dichos productos. ${ }^{14}$ La zona también empezó a destacar por su cría de ganado: de 550 reses exportadas a Nueva España entre 1751 y 1790 , la cifra se elevó a 4100 entre 1791 y 1800 , siendo Julián Icedo el principal ganadero de esta década. ${ }^{15}$

Esta leve reactivación de la economía, que giraba en torno a la producción de la sal, fue constante hasta el final de la etapa colonial. Esto puede observarse inclusive en los años críticos de 1785-1786, ya que mientras en otras partes los estragos causados por la crisis agrícola fueron devastadores, en Colima fueron menos desoladores. En 1787 Pérez Ponce de León informaba que la producción de sal y algodón había alcanzado niveles óptimos, no obstante la escasez de maíz. Según su testimonio, la insuficiencia de este grano no había llegado a alterar el orden público porque, a pesar del alza de precios, no faltó lo necesario para abastecer a los colimenses. ${ }^{16}$

Colima, al igual que otras ciudades de la América española, no se sustrajo de la fiebre argentífera de la época borbónica. Algunos empresarios de la localidad arriesgaron sus fortunas en la

14 Serrera, Guadalajara, 1977, pp. 5455.

15 Ibid., pp. 107 y 122.

16 "Descripción", 1979, p. 233. búsqueda y explotación de yacimientos, pero sin obtener resultados satisfactorios. Aquí valdría la pena citar al mismo Pérez Ponce de León, quien se dedicó a explotar las minas de oro, pla. ta, cobre y plomo que localizó en las serranías que rodeaban al valle de Tecalitlán. De esta manera, en 1787 se encontraban activos los reales de Santa María del Tabor, Gran Nombre de Dios, Las Plomosas, Río del Oro y Piziatlán. Sin duda que Pérez Ponce de León exageró la riqueza de dichas ve. tas, sobre todo de la última, pues llegó a asegurar que con el tiempo podía convertirse en la más rica de América. ${ }^{17}$ Seis años más tarde, Diego de Lazaga las describía como bastante pobres, de dificil acceso y rodeadas de una temperatura muy ardiente. ${ }^{18}$

Si a final de cuentas la producción minera resultó tan exigua que no estimuló la agricultura, la manufactura, ni tampoco atrajo a más inversionistas o a trabajadores interesados en esa actividad, mucho menos fue capaz de fomentar la inmigración.

El comercio tampoco pudo incrementarse debido a la ausencia de un mercado interregional bien integrado y por el número reducido de habitantes. Las principales casas comerciales, ubicadas en los portales que estaban alrededor de la plaza principal, eran pocas y modestas. El hecho de que los propietarios de estas tiendas se surtieran casi exclusivamente en los grandes almacenes de Guadalajara, permitió a los poderosos mercaderes tapatíos incorporar

\footnotetext{
17 Ibtd., p. 234.

${ }^{18}$ Lazaga, Descripctón, 1974, pp. 88, 90, 92, 95 y 100 .
} 
poco a poco el espacio colimense a su esfera de dominio. Y es que la cercanía con esta ciudad, y la lejanía con otros centros de consumo de importancia, influyeron para que Colima estableciera relaciones mercantiles preferente. mente con la capital neogallega y con la jurisdicción de Sayula. ${ }^{19}$

Guadalajara fue el único centro re. distribuidor de mercancías importadas en toda el área occidental y ejerció una poderosa influencia en todas la villas y poblados de esa zona, y Colima no fue la excepción. A esta situación preponderante se debe que casi la totalidad de los inmigrantes que arribaban a la región prefirieran establecerse en la capital neogallega y muy pocos en la villa colimense, no obstante su proximidad con el mar. Especialmente en el último cuarto del siglo XVIII, a los comerciantes tapatíos les atrajo más la idea de establecer sucursales en Colima. ${ }^{20}$ Fue tanto el interés que tuvieron por este mercado, que el Real Consulado de Guadalajara decidió en 1809 instalar una diputación en la villa colimense.

Durante esta época, en la villa de Colima sólo existían seis tiendas que monopolizaban el comercio regional. Estos almacenes, que distribuían efectos de Castilla y los productos de la región, pertenecían a peninsulares. Una de ellas era propiedad de Bernardo Quiroz.

${ }^{19}$ En 1807 el comerciante colimense Hilario Porrero sostenía negocios con mercaderes de Toluca. Pérez, Plata, 1988, p. 225.

${ }^{20}$ Uno de ellos fue Ramón Murúa.

\section{LA GRAN PROPIEDAD}

Desde el momento en que los conquistadores y los primeros colonizadores perdieron la esperanza de encontrar en Colima ricos yacimientos de oro y plata que les permitiesen conformar su patrimonio, la tierra se convirtió en la fuente principal de donde emanaba cualquier manifestación de poder. Poco a poco, a medida que se consolidaba el dominio sobre el suelo, fue conformándose una oligarquía cuya riqueza provenía de la explotación agrícola, de tal suerte que ya para esta centuria aparecen grandes propietarios, como es el caso de Juan Aguilar Solórzano, cuyos descendientes fueron de los primeros cultivadores de coco de agua. ${ }^{21}$

Entre los principales propietarios del siglo XVII figuraban Pedro López de Salazar, ${ }^{22}$ Pedro Alcaraz y los hermanos Jerónimo, A lonso y Juan Ochoa de Victoria. ${ }^{23} \mathrm{El}$ primero de ellos era dueño de una hacienda cercana a la villa de Colima y de "huertas, casas y esclavos";24 el segundo -regidor de Colima en 1637-, poseía una de las plantaciones de cacao más extensas que existian por aquel entonces. Por lo que respec-

${ }^{21}$ Aguilar Solórzano, propietario de las huertas de cacao de Xicotán, se casó con Ana Martell. Ma drid Castro, Colima Colonial 1978, pp. 25-26.

22 Una vez que murió su esposa, Agustina Alarcón, ingresó como novicio al convento de San Francisco. Tres de sus hijas - Francisca, Catalina y Magdalena- se casaron con los hermanos Ochoa de Victoria. Ibid, p. 48.

23 Hijos de Diego Ochoa de Victoria y de Inés de la Barrera. Los tres se casaron con hijas de Pedro López de Salazar.

${ }^{24}$ Madrid Castro, Colima colonial, 1978, pp. 46-47. 
ta a los hermanos Ochoa de Victoria, Jerónimo ${ }^{25}$ tenía en propiedad las haciendas del Trapiche, Montitlán, Juan Jiménez, La Estancia, Chapula y Cuatro Estancias; Alonso, ${ }^{26}$ que desempeñaba el cargo de regidor, poseía enormes terrenos en diferentes rumbos de la región, y Juan, ${ }^{27}$ alférez mayor por mucho tiempo, llegó a acumular predios muy vastos.

Mención aparte merecen Elvira Gamboa, quien en los albores de la centuria era propietaria de las huertas más importantes de cacao en el valle de Cajitlán, ${ }^{28}$ y Juan de Solórzano, dueño de las huertas de Achis. tlán, Jicotlán y Zapotlanejo, donde cultivaba este mismo producto, y de las estancias de Tecolapa y Sacalpan; en este último lugar tenía, en 1602, cerca de 900 vacas y 50 yeguas. ${ }^{29}$

Otro de los principales propietarios del primer cuarto del siglo Xvil fue Martín Alonso Enríquez, regidor de la villa de Colima, en donde poseía varias casas; en el valle de Cajitlán tenía una

25 Se casó con Catalina López de Salazar, hija legítima de Pedro López de Salazar y de Agustina de Alarcón. Al desposarse recibió de dote 20000 ducados de oro. Una de sus hijas, Manuela, se unió en matrimonio con Julio de Hoyos y Velasco. Ibid, p. 55.

26 Casado con Magdalena López de Salazar.

27 Se unió en matrimonio con Francisca ló pez de Salazar. Su hija Agustina se casó con el capitán José Beltrán Vicente, e Isabel con Juan de Heredia. Madrid Castro, Colima colontal, 1978 , p. 59.

28 Gamboa testó ante el escribano Mateo de Sepúlveda el 15 de diciembre de 1600. Ibid, p. 31.

29 Juan Solórzano fue hijo de Cristóbal Solór. zano y de María de Grijalva. Estuvo casado con Isabel Silva. Al enviudar se casó con Isabel de Arellano. Ibtd, pp. 32-36. huerta de cacao y palmeras de cocos. Al parecer su fortuna era considerable, pues su patrimonio le permitió enviar a sus hijos Francisco y Martín a estudiar a la ciudad de México. ${ }^{30}$

Para el siglo XVII el clero también se había convertido en poseedor de extensiones muy vastas: la hacienda de Los Pastores pertenecía a la Compañía de Jesús del Colegio de Tepozotlán; la de San Ignacio era propiedad de los jesuitas de Guadalajara; la Albarrada y Quesería formaban parte de los bie. nes de los mercedarios, y La Capacha correspondía al convento y hospital de San Juan de Dios. ${ }^{31}$

Tal y como ocurrió en otras latitudes, a principios del siglo XVIII, la gran propiedad ya se encontraba bien consolidada como resultado de la conquista, la herencia, la compra, el matrimonio y la usurpación de los bienes de los indigenas. Una de las principales haciendas de esta época fue La Estancia Vieja, perteneciente a María Francisca Pérez de Ayala. ${ }^{32}$ Pero quizá la familia más poderosa de esta centuria sea la Brizuela. En 1702, Nicolás de Brizue. $1 \mathrm{la},{ }^{33}$ alcalde mayor de la villa de Colima, poseía una hacienda de palmas en el valle de Nahualapa, un sitio de ganado mayor conocido como Cuximitla que colindaba con las estancias de Montitlán y La Albarrada, una estancia de ganado mayor que tenía una exten-

30 Casado con Bartola Angulo. Ibid, p. 44.

${ }^{11}$ Peña, Oligarquía, 1983, p. 67; Madrid Castro, "Apuntes".

32 Este latifundio lo heredó de su tío Francisco Pérez de Ayala, cura de la villa de Colima. Guzmán, Colima, 1973, p. 180.

33 Hijo del capitán Rodrigo de Brizuela y de Leonor Barroso de Tene. 
sión de 1750 hectáreas y 40 pozos de sal en la jurisdicción de Tecomán. ${ }^{34}$ Los descendientes de Nicolás fueron aún más poderosos. Bartolomé de Brizuela, ${ }^{35}$ por ejemplo, llegó a ser propietario de El Llano, Nahualapan, Cuyrutlán, Tlila, Suchitlán, y de otros terrenos inmediatos a la villa colimen. se. Las haciendas de Nogueras, El Trapiche y La Huerta pertenecían al coronel Juan Antonio Brizuela, hijo de Bartolomé, quien se unió en matrimonio con María Francisca Pérez de Ayala. ${ }^{36}$

No parece que haya habido otro latifundista tan poderoso como Bartolomé de Brizuela. Gran parte de sus terrenos ubicados por el lado de la costa estuvieron dedicados a la siembra de palmas de coco, principalmente los de la hacienda de Nahualapan, en donde se elaboraba "vino de palma". Sin embargo, no todas las propiedades de Brizuela estaban bien regularizadas, sobre todo la hacienda de Cuyutlán ofre. cía muchas confusiones que hacían sospechar que la detentaba ilegalmente. Tan fue así que en 1780 el Consulado de México, basándose en esta anomalía, la remató. Pedro Romero de Terreros, conde de Regla, adquirió la finca junto con las haciendas Los Pastores, San Andrés Periquillo y Santa Rosa; las estancias de Armería, Coalata y EI Colomo, y los terrenos de Ihuitlán y La Albarrada ubicados en Coalcomán y Tonila respectivamente. ${ }^{37}$

Otro de los vástagos de Bartolomé $79-81$.

${ }^{34}$ Madrid Castro, Colima colontal, 1978, pp.

35 Casado con Josefa de Luna.

36 Guzmán, Colima, 1973, p. 181.

37 Ibid. fue Diego de Brizuela. ${ }^{38}$ Además de ser propietario de grandes extensiones, figuraba como uno de los principales comerciantes de la villa de Colima que proporcionaba créditos a pequeños mercaderes de la localidad.

Una hacienda importante fue la de Santa Cruz de Tacalahuasta, perteneciente a Juan Ascencio de Bobadilla, en donde existía uno de los trapiches más productivos de la región. Bobadilla era también propietario de la hacienda de San Joseph de Amatitlán, ubicada en la jurisdicción de Sayula. ${ }^{39}$ Francisco Sánchez es otro de los hacendados notables: el 2 de diciembre de 1790 , Nicolás Vaquero en nombre de Victoriano de Jaso, denunció como realengos los puestos de Guitumba, Cataquio, Guitumbilla, Coaquispala y El Sombrero que, en conjunto, abarcaban una extensión de once sitios de ganado mayor, pero en el remate que se hizo no pudo quedarse con ellos porque Sánchez superó la oferta. Por 3570 , éste se apropió de los terrenos mencionados. ${ }^{40}$

Otro de los individuos cuyo poder estaba fincado en la posesión de grandes extensiones de tierra fue Francisco Guerrero del Espinal. Avecindado en Colima desde 1792, comenzó adminis-

38 Se casó por primera vez con Beatriz Vargas, y en segunda ocasión con María Francisca de Salcedo. Esta última introdujo al matrimonio 10000 pesos, y él 25000. Madrid Castro, Colima colontal, 1978 , p. 97.

39 Bobadilla estuvo casado con Manuela de la Roja y Bara, hija de Alonso de la Bara y anterior propietario de la hacienda de San Joseph de Amatitlán. AIPJ, Libro de Gobierno, tomo 26, fojas $17 \mathrm{v} 21 \mathrm{v}$.

40 AIPJ, "Tierras y aguas", Primera seric, libro 51 , exp. 1. 


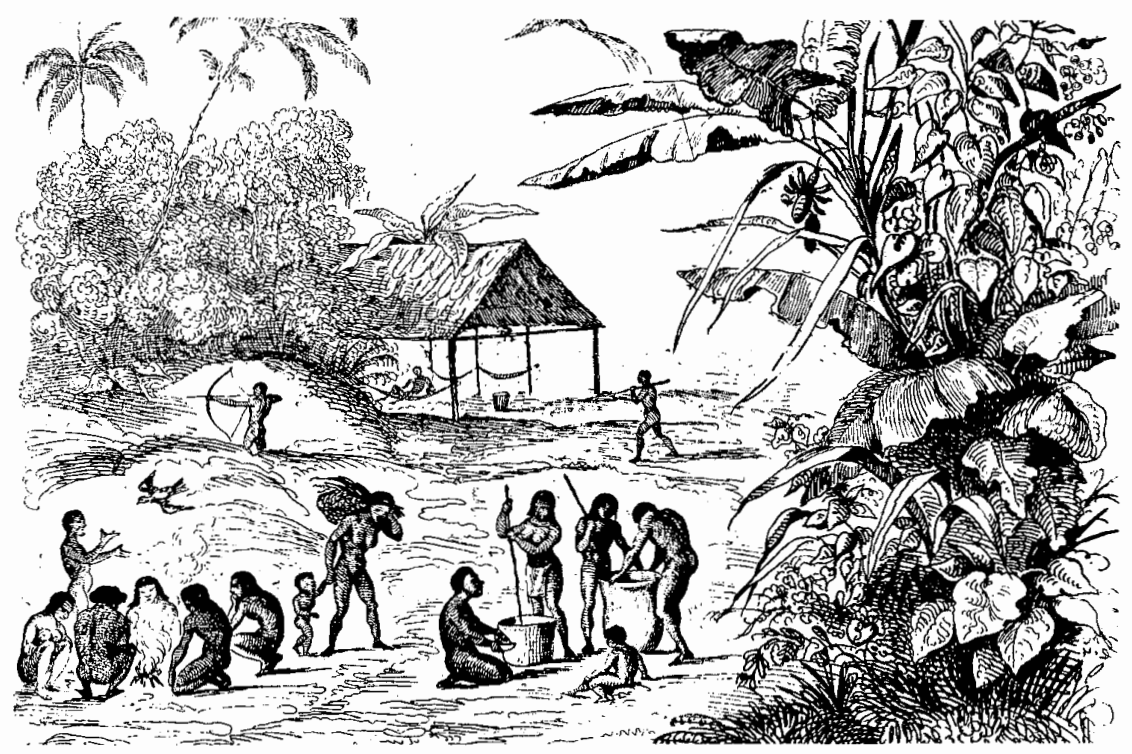

trando las haciendas de los descendientes del conde de Regla, pero a partir de 1800 empezó a adquirir grandes propiedades, entre ellas las haciendas de La Magdalena, La Joya y los terrenos de El Peregrino, Llano de Santa Juana y El Espinal. En la villa de Colima adquirió en 1798 parte del portal Los Arcos propiedad de Guadalupe Escandón, viuda de Lago, que estaba situado frente a la plaza principal (hoy portal Morelos). También compró el portal que actualmente se llama Medellín. ${ }^{41}$

Por último, vale la pena mencionar a José Trinidad Salcedo, propietario de la hacienda agroganadera La Capacha y de pozos de sal en El Guayabal y Lo de

${ }^{41}$ Guzmán, Colima, 1973, p. 181.
Vega, ${ }^{42}$ y a Bartolomé de Cosío, quien se dedicó al comercio de esclavos. Cuando murió la esposa de éste, Agustina Beltrán Vicente, en 1774, el patrimonio familiar lo integraban una casa, una tienda en Colima, la hacienda San José del Trapiche gravada con 9866 pesos a favor de Diego Beltrán Vicente y ¡más de 50 esclavos! ${ }^{43}$

\section{LA INCORPORACIÓN A MiCHOACÁN}

A pesar de la ligera reactivación que

42 Estuvo casado con Gertrudis Lobo. Emparentó con la familia Brizuela cuando su hija Maria se casó con Diego. Madrid Castro, Colima colonial, 1978, pp. 100-101.

43 Ibid, pp. 93-95. 
experimentó la economía en el último tercio del siglo XVIII debida al repunte mercantil y al cultivo de nuevos productos, el trigo, por ejemplo, Colima no pudo superar del todo su crónico anquilosamiento. El aislamiento, la inexistencia de un mercado local bien integrado, las dificultades geográficas y los problemas fiscales y de transporte, impidieron la ampliación de la red mercantil y siguieron favoreciendo el desarrollo de una economía casi de autoconsumo. En el informe de 1787, Pérez Ponce de León ya hacía notar al virrey que Colima era "digna de la superior atención del gobierno", y para entusiasmar a las autoridades novohispanas comunicaba que en los puertos de Santiago, Manzanillo y San Telmo había ricos bancos de perlas que podrían aumentar considerablemente el "real haber de su majestad". 44

El eterno lamento de los colimenses respecto a los perjuicios que les ocasionaba la distancia que los separaba de la capital del virreinato pareció tomarse en cuenta en la real cédula del 4 de diciembre de 1786 , la cual dividía el territorio novohispano en doce intendencias. De acuerdo con la nueva división político administrativa, la alcaldía mayor de Colima, pero ahora como partido, pasó a formar parte de la intendencia de Valladolid. Su jurisdicción estuvo integrada por una villa, catorce pueblos, una congregación, tres reales de minas, ocho curatos, diez haciendas, $y$ varios ranchos y estancias de ganado. ${ }^{45}$ No obstante este reacomodo, el crónico aislamiento de Coli-

46 Descripción", 1979, p. 235.

45 Guzmán, Colima, 1973, p. 196. ma no pudo romperse, porque también resultó muy difícil la comunicación con Valladolid. En efecto, la falta de un camino expedito impidió el contacto regular entre la nueva cabecera política y el partido, de tal manera que los colimenses siguieron quejándose de la confinación en que permanecía su región con respecto de los grandes centros de consumo.

Quienes resultaron favorecidos con las nuevas disposiciones fueron Ios ricos comerciantes de Guadalajara, porque aprovechando la nueva política del libre comercio abastecieron con más regularidad a los mercaderes colimenses. Fue precisamente la práctica constante del intercambio mercantil lo que fue ligando poco a poco la villa de Colima más a Guadalajara que a Valladolid, circunstancia que a la postre sirvió para que los empresarios tapatíos reforzaran su predominio.

Incluso todo parece sugerir que la producción de Colima poco a poco se fue ajustando a las necesidades de Gua. dalajara. Ya se ha dicho, por ejemplo, que cuando los talleres textiles ubicados en esta ciudad comenzaron a incre. mentar su producción y demandaron una mayor cantidad de materia prima -algodón-, el Real Consulado promovió el cultivo de este producto en Colima, junto con el del añil. Y para transportarlos con rapidez y oportunamente, el Tribunal Mercantil reparó la ruta que unía a estos dos puntos. ${ }^{46} \mathrm{Al}$ darse cuenta los comerciantes y las autoridades tapatias de la importante función que ejercía Colima en la economía neogallega al proveerla de pro-

${ }^{46}$ Serrera, Guadalajara, 1977 , pp. $54-55$. 
ductos que muy poco se cultivaban en su territorio como el coco, el cacao, la sal y el algodón, por ejemplo, comenzaron a fraguar la idea de incorporarla políticamente a su jurisdicción.

Un paso trascendental en la conquista de este objetivo lo dio fray Antonio Alcalde, obispo de Guadalajara, al gestionar ante la corona española que los curatos de La Barca, Zapotlán el Grande y Colima, entonces pertenecientes a la diócesis de Michoacán, fueran agregados a la jurisdicción de la mitra neogallega. Para acelerar el asunto, el prelado envió a la ciudad de México al dean Salvador de la Roca, a quien le proporcionó 14000 pesos para que cubriera todos los gastos que se presentaran. ${ }^{47}$

A mediados de 1787 , en cuanto se percataron de las pretensiones de Alcalde, las autoridades civiles y eclesiásticas de Colima comenzaron a manifestar su oposición a tal propósito, señalando

el justo temor de que serán tan desaten. didas por el obispado de Guadalajara, como lo son, $y$ han sido de muchos años a esta parte, los pueblos de Armería, Cuatlan, y numerosa población de $\mathrm{Cu}$ yutlán pertenecientes a Guadalajara, que se hallan abandonados sin un sacerdote siquiera, dependientes solamente de los auxilios espirituales que les presta el cura de Cajitlán que es de Valladolid. 48

Ciertamente los colimenses tenían razón al exponer que el obispo de Gua.

47 Santoscoy, Obras, 1984, p. 197.

48 Archivo General de la Nación (AGN), Serie Clero regular, vol. 35 , exp. 1 , f. 1 . dalajara mantenía en completo abandono a los fieles de esas poblaciones, ya que por la falta de sacerdotes, por su avanzada edad y su mal estado de salud, no había podido atender como era debido las necesidades espirituales de esa grey. Uno de los que más se opusieron a que Colima pasara a depender de la diócesis neogallega fue José Miguel Pérez Ponce de León, quien para entonces había regresado a ocupar el mando político. ${ }^{49}$ Tanto él como los demás feligreses manifestaron repetidamente estar muy complacidos de pertenecer al obispado de Michoacán porque siempre habían recibido una atención muy especial. ${ }^{50}$ Por tanto, dudaban "ser mejorados en caso de unirse esta provincia a la de Guadalaja. ra, y más bien seríamos grandemente perjudicados [...]".51

Finalmente, los deseos de Alcalde fueron cumplidos al disponer Carlos IV, el 17 de abril de 1789, que los curatos de La Barca, Ayo el Chico, Atotonilco, Ocotlán, Zapotlán el Grande, Tamazula, Colima, Almoloyan, Ixtlahua. cán y Caxitlán, pertenecientes hasta entonces al obispado de Valladolid, pasaran a formar parte de la diócesis de Guadalajara por encontrarse más proximos a ésta. Como la mitra michoacana se negó a ceder dichos curatos, la Audiencia de México envió a un visitador para que estudiara el caso y rindiera un dictamen al respecto, el cual, a final de cuentas, fue favorable pa-

49 loid.

50 Colima se mantenía incorporada al obispado de Valladolid desde el 8 de agosto de 1536. Brambila, El obispado, 1964, p. 40.

${ }^{51}$ AGN, Serie Clero regular, vol. 35, exp. 1, f. 6. 
ra Guadalajara. El virrey dispuso entonces- 10 de julio de 1794- el cumplimiento de la cédula del 17 de abril de 1789. Pero aun así las autoridades eclesiásticas de Michoacán, resentidas por el desmembramiento, procedieron con mucha lentitud en las gestiones para hacer el traspaso formal, lo que dio lugar a que el cabildo eclesiástico de Guadalajara se disgustara profundamente. Aquéllas, por ejemplo, retardaron deliberadamente la publicación de la cédula real en los curatos segregados, provocando con ello una gran confusión porque los habitantes de esos lugares no sabían a ciencia cierta a dónde debían enviar el producto de los diezmos.

Mientras se hacían las gestiones correspondientes, se recrudecieron las relaciones entre el obispado de Guadalajara y el de Valladolid. Con frecuencia el primero acusó al segundo de no publicar algunas bulas pontificias en los curatos de La Barca, Zapotlán y Colima, en represalia por haber cercenado su jurisdicción. ${ }^{52}$ Finalmente, la en. trega oficial de los diez curatos tuvo lugar el 20 de julio de 1796.53

Así las cosas, los colimenses tuvieron que trasladarse a Guadalajara para atender sus asuntos eclesiásticos y a Morelia para resolver los problemas políticos y administrativos. Emesto Lemoine es otro de los historiadores que analiza la situación ambivalente que vivieron los habitantes de Colima durante el periodo colonial. Lemoine la describe como una zona intermedia, que por estar rodeada de dos ambientes culturales de acusada

52 Ibid., f. 2744.

53 Guzmán, Colima, 1973, p. 195. personalidad -Guadalajara y Michoacán-, no acababa de ser neogalaica ni dejaba de ser michoacana. ${ }^{54}$

\section{EN LAS POSTRIMERIAAS DEI SIGLO XVIII}

Ya se ha dicho que poco antes de que Colima se agregara en lo político a Michoacán, Miguel José Pérez Ponce de León volvió a hacerse cargo del gobierno varias veces durante el periodo de marzo de 1787 a fines de 1788 . Lo sucedió Luis de Gamba y González, a quien correspondió ser el primer subdelegado del partido, cargo que desempeñó del 31 de marzo de 1789 hasta principios de 1796, exceptuando algunos lapsos cortos. De Gamba y González, también con fama de ilustrado, se encargó de aplicar las primeras disposiciones políticas, administrativas y hacendarias prescritas en las $\mathrm{Or}$. denanzas de Intendencias. 55

Durante su gobierno arribó a Colima el coronel Diego de Lazaga en 1791, quien venía con el encargo de elaborar una relación económica, política y geográfica de todos los pueblos, ranchos, estancias, congregaciones y puertos que se ubicaban en toda la costa del Mar del Sur desde Acapulco hasta San Blas, tarea que concluyó a principios de 1793. En la Relación de Colima, Lazaga volvió a mencionar los complejos problemas derivados del aislamiento en que vivía la región y, al igual que Pérez Ponce de León, señaló que para salir de ese anquilosa-

54 Véase su libro Morelos, 1979, p. 215.

55 Guzmán, Colima, 1973, pp. 195-196. 
miento se requería que el virrey le brindara más atención.

Colima, en efecto, mantenía un atraso notable en comparación con otros partidos. A excepción de la cabecera política, en donde se podía observar cierta actividad, en las demás poblaciones la vida transcurría en medio de una monotonía desalentadora. Pero aun así, la imagen que proyectaba la villa de Colima era muy modesta. Entre 1791 y 1793 contaba con 4314 habitantes, de los cuales 1939 eran españoles y criollos, 85 castizos, 181 mestizos y 2109 mulatos. ${ }^{56}$

Como ocurría en todas las ciudades novohispanas, las familias de los españoles pudientes vivían en las calles que circundaban la plaza principal; frente a ésta se hallaban la parroquia, las casas reales y la cárcel; en los otros tres costados se encontraban portales cons. truidos de madera y teja, en donde es. taban instaladas las principales tiendas de la villa. El resto de las construcciones, donde moraban mestizos, indios y pardos, eran bajas, húmedas y mal ventiladas, pero casi todas con huertas frutales. Había dos conventos, el de la Merced y el de San Juan de Dios; aparte de la parroquia, los fieles disponían de otras dos iglesias, la del Dulce Nombre de Jesús y la de San Felipe de Jesús.

El Ayuntamiento estaba integrado por dos alcaldes ordinarios, dos regidores y un procurador del común. Los fondos que recaudaba eran tan escasos que, con mucha frecuencia, los ediles informaban a la superioridad que los ingresos ni siquiera alcanzaban para cubrir los gastos más elementales.

56 Lazaga, Descrtpct6n, 1974, p. 100.
En San Francisco Almoloyan vivian 310 españoles, 113 castizos, 116 mestizos y 886 mulatos; en Cajitlán, residian 33 españoles, cinco castizos, siete mestizos y 66 mulatos; en Ixtlahuacán, nueve españoles y un mestizo; en la congregación de Tecalitlán, 387 españoles, once castizos, 45 mestizos y 781 mulatos; en el Real del Tabor, 260 españoles, quince castizos, dos mestizos y 255 mulatos; en Jilotlán, cuatro españoles y tres mulatos; en el Real del Sombrero, 100 españoles, nueve castizos, trece mestizos y 94 mulatos; y en el Real del Oro, 176 españoles, un castizo, trece mestizos y 54 mulatos.

En otro informe previo a la Descripción, Lazaga notificaba que en la hacienda de Armería tan sólo había seis familias que daban un total de 18 habitantes, y que en las salinas de Cuautlán no había moradores fijos,

solamente cuando se beneficia este ramo -la sal-, concurren a ellas algunas gentes de Colima, Zapotlán y otros parajes, pero luego que concluyen se retiran a sus domicilios dejando los parajes sin más personas que los que cuidan los almacenes ínterin encierran la sal[... $]^{57}$

La población total del partido, incluyendo la que vivía en haciendas y ranchos, ascendía a 16419 habitantes. ${ }^{58}$ Lo que más llama la atención desde el punto de vista social y demográfico es el número elevado de mulatos, cuyo porcentaje a fines del siglo XVIII alcanzaba el 43\%. Otra fuente nos indica que para 1794 en el te-

57 AGN, Serie Clero regular, vol. 35, exp. 1, fs. 18-19.

58 Lazaga, Descripcion, 1974, pp. 100-101. 
rritorio de Colima había doce pueblos, 24 haciendas y 38 ranchos, donde moraban 15633 almas. 59

Entre otras cosas, Lazaga resaltaba dos elementos del carácter de los colimenses: el primero se refiere a la desidia o la indiferencia que tenían hacia el trabajo; el segundo, a la "ferocidad" de su temperamento que los empujaba a cometer todo tipo de delitos y a desatender a la "autoridad real y al espíritu de las leyes", de tal suerte que "se vive sin Dios, sin ley, ni rey, pues no conocen otra ley que el más poderoso que tienen a la vista". ${ }^{\circ}$ Podría afirmarse que la inercia y la violencia a que hace alusión este autor se había arraigado desde los primeros años de la colonización a consecuencia del aislamiento y el abandono en que se mantuvo a Colima.

Los distintos alcaldes mayores siempre se sintieron alejados del centro politico, sinapoyoy sin recursos para hacer cumplir la ley. Frente a esta situación, los gobernados no veían con respeto a la autoridad y delinquian a la primera provocación, confiados en que no recibirían ningún castigo. Las seis compañías militares que existian -cuatro en Colima, una en San Francisco Almoloyan y una en Tecalitlán-, nada pudieron hacer para mantener el orden, pues carecían de armamento suficiente. ${ }^{61}$ Lazaga consideró que "sólo un mando sostenido y activo" podía templar y moderar "los arrojos que [los habitantes] están acostumbrados a ejercer con frecuencia" ${ }^{62}$

59 Urrutia, "Noticia", 1973, p. 84. Véase también Gerhard, Geografía, 1986, p. 84.

60 Lazaga, Descripcion, 1974, p. 90

61 Guzmán, Colima, 1973, p. 197.
Por todo esto fue muy difícil que los funcionarios aplicaran con éxito las reformas políticas, administrativas y económicas de los Borbones. Sacar a Colima de ese atolladero y vincularla más directamente a la economía novohispana, implicaba enfrentarse entre otras cosas al modus vivendi de la po. blación. Pese al esfuerzo emprendido por varias autoridades para remediar la situación, poco o nada se avanzó al respecto, no obstante que la nueva política de los Borbones estaba orientada precisamente a ejercer un mejor control y a afianzar la situación colonial.

Además, con la nueva organización político-administrativa (intendencias), la corona española tuvo una vigilancia más estrecha sobre la población. Conforme al esquema borbónico, los intendentes y los subdelegados de cada partido figuraban como instrumentos de control social. A diferencia de los antiguos alcaldes mayores, que habían incurrido en numerosos actos de corrupción y abuso de autoridad al pagarse a sí mismos los servicios que prestaban o al controlar el comercio de sus respectivas jurisdicciones, los subdelegados tuvieron menos posibilidades de cometer atropellos gracias a la supervisión del intendente. Como es sabido, muchos alcaldes mayores, al manejar toda la actividad mercantil, ejercieron un dominio absoluto sobre sus respectivas localidades. ${ }^{63}$

62 Lazaga, Descripción, 1974, p. 90.

${ }^{63}$ Los frecuentes abusos que cometieron los alcaldes mayores fueron razones de peso para que la Audiencia de México promoviera juicios de residencia en contra de ellos. El 16 de febrero de 1717, por ejemplo, Fernando Antonio Cane- 
Es de sobra conocido que las reformas borbónicas estuvieron por un lado orientadas a reafirmar el control de España sobre sus colonias, y por otro lado a impulsar la economía de éstas para obtener mayores ingresos. Sin em. bargo, no en todas las regiones se experimentaron los mismos resultados; en Colima, por ejemplo, los estímulos provenientes desde fuera no fueron suficientes para superar el estancamiento, la escasez de población y la falta de inversiones. De cualquier manera no debe pensarse que el impacto que provocó el libre comercio en la región haya sido muy restringido. Es cierto que la ausencia de un puerto para importar y exportar, la falta de capitales, la pobreza de la mayoría de los habitantes, que se reflejaba en un consumo reducido, y la competencia que ofrecía Guadalajara, limitaron la expansión. Pero a pesar de eso Colima experimentó una ligera reactivación económica, -en comparación con el largo periodo de los Austrias-, la cual puede apreciarse en el aumento de la recaudación de las alcabalas que se registró hasta que estalló la guerra de Independencia (véase cuadro 1 ).

Si bien es cierto que el reformismo borbónico no estimuló la economía colimense en la misma proporción que en otros lugares, sí logró en cambio que sus habitantes cobraran plena conciencia de los daños que les ocasionaba la situación que había engendrado la dependencia política. Por otro lado, el

te, que había obtenido el cargo por 1400 pesos en remate público, fue sometido a un proceso. Lo sucedió Fernando Bueno de Viveros.AIPJ, Libro de Gobierno, tomo 35, 97v101 v. impulso que estaba cobrando la actividad mercantil en todo el continente americano influyó para que los colimenses empezaran a proyectar el futuro de la villa en función de Manzanillo. A partir de entonces quedaron conven. cidos de que este puerto podría fortalecer a Colima en la misma medida que San Blas contribuía a la vigorización de Guadalajara; por tanto, la idea de conseguir la habilitación de Manzanillo empezó a cobrar forma en la mente de quienes controlaban la producción.

Pero al lado de estos primeros bal. buceos, encaminados a adquirir cierta autonomía, se daban algunos intentos que procuraban estrechar más a Coli. ma con la capital neogalaica. Por ejemplo, a mediados de 1793, Luis de Gamba y González trató de conseguir la autorización para que los tributos que pagaban los indígenas, en lugar de remitirlos a las cajas reales de Valladolid, se enviaran a las de Guadalajara. Las razones que expuso el subdelegado para obtener la autorización, fueron las siguientes: la enorme distancia que había de por medio entre Colima y Valladolid -100 leguas-y "la falta de correspondencia" entre ambas ciudades; en cambio, de Gamba y González subrayaba que la entrega de dichos fondos podía ser más fácil si se mandaban a la capital tapatía porque la distancia era menor, los caminos estaban en mejores condiciones y porque Colima mantenía una relación mercantil muy estrecha con esa ciudad. ${ }^{64}$

Los tributos recaudados eran apor.

64 Véase AGN, Serie Tributos, vol. 48, exp. 8. 


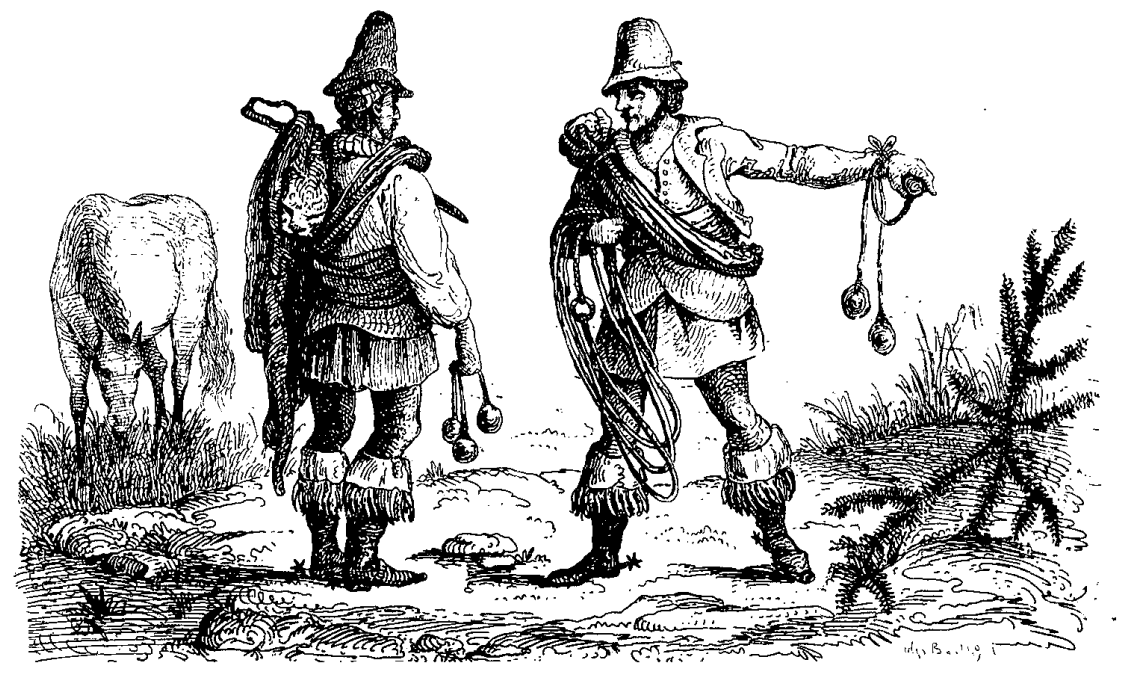

tados por los indios que vivían en $\mathrm{Xi}$ cotlán, Cuautlán, Ixtlahuacán, Tamala, Tecomán, Cajitlán, Almoloyan, Comala, Coquimatlán, Quizalapa, Xuluapan, Xuchitlán y Zacualpan. ${ }^{65}$ Las cantidades reunidas en estos pueblos fueron enviadas a Valladolid hasta 1795; al año siguiente empezaron a remitirse a las cajas de Guadalajara, una vez que la Junta Superior de la Real Hacienda aprobóla proposición de Gamba y González ${ }^{66}$ (véase cuadro 2 ). Este acuerdo significó la incorporación política del partido de Colima a la intendencia de Guadalajara ${ }^{67} \mathrm{~A}$ partir

65 Guzmán, Colima, 1973, p. 203.

${ }^{66}$ AGN, Serie Tributos, vol. 48, exp. 8, fs. 365 376.

67 Serrera, Guadalajara, 1977, p. 20; Bravo, de ese año, el control que ejercían los neogallegos sobre el área colimense cubría ya todos los aspectos: el eclesiástico, el económico y el político.

Mientras ocurría este reacomodo territorial, en el valle de Tecomán se registraban algunos cambios dignos de tomarse en cuenta: Cajitlán, que había figurado hasta entonces como la pobla. ción más importante de esta región, empezó a decaer como centro comercial y religioso. Las causas del declive

Historia, 1963, p.162; Guzmán, Historia, 1970, p. 39; Vizcarra, Apuntes, 1949 ,p. 54. En cambio, José María Muriá asegura que fue durante la guerra de Independencia cuando Colima quedó ligada políticamente a Guadalajara, Historia, 1976, pp. 49-50. 
Cuadro 1. Recaudación de alcabalas 1777-1811

$\begin{array}{lrrr}\text { Año } & \text { Cantidad } & \text { Año } & \text { Cantidad } \\ & & & \\ 1777 & 2882 & 1795 & 17871 \\ 1778 & 12776 & 1796 & 17871 \\ 1779 & 13325 & 1797 & 19832 \\ 1780 & 13619 & 1798 & 18829 \\ 1781 & 12481 & 1799 & 16401 \\ 1782 & 16778 & 1800 & 18308 \\ 1783 & 11519 & 1801 & 29380 \\ 1784 & 14403 & 1802 & 26364 \\ 1785 & 15322 & 1803 & 35627 \\ 1786 & 9321 & 1804 & 45241 \\ 1787 & 10286 & 1805 & 44002 \\ 1788 & 11537 & 1806 & 54723 \\ 1789 & 22053 & 1807 & 70409 \\ 1790 & 18541 & 1808 & 64303 \\ 1791 & 11231 & 1809 & 68894 \\ 1792 & 16252 & 1810 & 55179 \\ 1793 & 14319 & 1811 & 30308 \\ 1794 & 15017 & & \end{array}$

Fuente: Juan Carlos Garavaglia y Juan Carlós Grosso, Las alcabalas novohispanas (1776-1821), Archivo General de la Nación/Banca Cremi, México, 1987, pp. 229-236.

Cuadro 2. Tributos de indios recaudados en Colima entre 1790 y 1795

$\begin{array}{rrr}\text { Tributo asignado } & \text { Cobrado } & \text { No cobrado } \\ 4150.0 .6 & 3248.2 & 901.6 .6 \\ 4150.0 .6 & 1339.0 .3 & 2811.0 .3 \\ 4149.5 .9 & 2540.7 .3 & 1608.6 .6 \\ 5599.5 & 2551.1 & 3048.4 \\ 45464.2 .7 & 13245.5 .8 & 32216.8 .9 \\ 45464.2 .7 & 13245.5 .8 & 32216.8 .9\end{array}$

Fuente: AGN, Serie Tributos, vol. 48, exp. 8, fs. 164-411. 
se atribuyen al clima extremoso y a la insalubridad, razones por las cuales los habitantes empezaron a abandonar el lugar para establecerse en Tecomán. Para el año de 1800 , Cajitlán se había despoblado tanto que dejó de ser cabecera parroquial; esta jerarquía le fue conferida a Tecomán, donde se habían congregado numerosas familias. En los albores del siglo XIX ya era evidente la decadencia de Cajitlán y el repunte de Tecomán. ${ }^{68}$

Otra de las poblaciones que fue adquiriendo importancia fue Valenzuela. Su ubicación estratégica a ambos lados del camino que unía la villa de Colima con la costa, fue determinante en su reactivación. En general, a principios del siglo xux la población se había incrementado en todo el partido: en el curato de Colima vivían 10 447; en el de San Francisco Almoloyan, 7 044; en el de Ixtlahuacán de los Reyes, 1333 ; en el de Santiago de Tecomán, 1060 , y en el curato de Jilotlán, $946 .{ }^{69}$ Este aumento demográfico se vio interrumpido a raíz del estallido de la guerra insurgente, porque aparte del ambiente de inseguridad que empezó a predominar, algunos colimenses emigraron a Guadalajara. ${ }^{70}$

En el turbulento y contradictorio siglo XIX, Colima tuvo que seguir resolviendo múltiples problemas a fin de superar los estragos ocasionados por el estancamiento económico y la dependencia política que mantuvo durante la época colonial.

68 Urzúa, Colimán, 1970, pp. 119-161.

69 Véase "Descripción eclesiástica", 1979. pp. 271.289.

70 Cook, Las migraciones, 1970, p. 361.
Bibitografía

-Brading, David A., Mineros y comerciantes en el México borbbnico, Fondo de Cultura Económica, México, 1975.

- Brambila, Crescenciano, El obispado de Colima, ed. del autor, Colima, 1964.

-Bravo Ugarte, José, Historia sucinta de Michoacán, Jus, México, 1963 (Col. México Heroico, 15).

-Calderón Quijano, Jose Antonio (dir.), Documentos para la historia del estado de Colima, Novaro, México, 1979 (Col. Peña Colorada).

-Consulta que el C. Lic. Ignacio Luis Vallarta y otros varios letrados, dan al $C$. Fermín Gómez Farías, representante del C. Manuel de la Pedreguera Romero de Terreros, con motivo del despojo de las salinas de Cuyutlán, dictado y llevado a efecto por el prefecto de Colíma D. José María Mendoza, en la época del imperio, $y$ consentido $y$ apoyado en la actualidad por el C. Ramón de la Vega, gobernador del mismo estado, Tip. Económica de Luis P. Vidaurri, Guadalajara, 1868.

-Cook, Sherburne F., "Las migraciones en la historia de la población mexicana", en García, Historia y sociedad, 1970.

- "Descripción del distrito de Colima y del corregimiento agregado de San Miguel de Jilotlán, $17761777^{\prime \prime}$, en Calderón, Documentos, 1979.

- "Descripción eclesiástica de Colima. Visita de 1802", en Calderón, Documentos, 1979.

-Florescano, Enrique e Isabel Gil (comps.), Descripciones económicas generales de Nueva España. 1784-1817, SEP/INAH, México, 1973 (Fuentes para la historia económica de México, 1.)

-García Martínez, Bernardo et al., Historia y sociedad en el mundo de habla española. Homenaje a José Miranda, El Colegio de México, México, 1970.

- "General noticia de todas las jurisdicciones de esta Nueva España, temperamen- 
tos, frutos y obispados, tributos y tributarios (1784)" en Florescano, Descripciones, 1973.

- Gerhard, Peter, Geografía histórica de la Nueva España, 1519-1821, UNAM, México, 1986 (Espacio y Tiempo, 1).

-Guzmán Nava, Ricardo, Colima en la historia de México. La colonia, Talleres Gráficos de México, México, 1973, t. III. - Historia de Colima, Ed. del Gobierno del Estado Libre y Soberano de Colima, Colima, 1970.

-Lazaga, Diego de, Descripción geográfica del partido de Colima, Talleres de Galas, México, 1974 (Col. Peña Colorada).

-Lemoine, Ernesto, Morelosy la revolución de 1810, Ed. Gobierno del Estado de Michoacán, Morelia, 1979.

-Madrid Castro, Alfonso de la, Colima colonial a través de sus testamentos y archivos, Vidriales Editores, México, 1978 (Club del Libro Colimense, 18).

- "Apuntes históricos. Haciendas colimenses en el siglo XVI" (mecanoescrito).

-Muriá, José Maria, Historia de las divi. siones territoriales de Jalisco, INAH, México, 1976 (Col. Científica, 34).

-Peña, José F. de la, Oligarquía y propiedad en Nueva España, 1550-1624,
Fondo de Cultura Económica, México, 1983.

-Pérez Herrero, Pedro, Plata y libranzas. La articulación comercial del México borbónico, El Colegio de México, México, 1988.

-Pérez Mallaína Bueno, Pablo Emilio, "Estudio a la descripción del distrito de $\mathrm{Co}$ lima y del corregimiento agregado de SanMiguel de Jilotlán. 1776-1777", en Calderón, Documentos, 1979.

-Santoscoy, Alberto, Obras Completas, Unidad Editorial del Gobierno de Jalisco, Guadalajara, 1984, t. I.

-Serrera, Ramón María, Guadalajara ganadera. Estudio regional novohispano 1760-1805, Escuela de Estudios Hispanoa. mericanos de Sevilla, Sevilla, 1977.

-Urzúa Orozco, Roberto, Colimán, Caxitlán y Tecomán, Editorial Jus, México, 1970.

-Urrutia, Carlos de, "Noticia geográfica del reino de Nueva España y estado de su población, agricultura, artes y comercio (1794)", en Florescano, Descripciones, 1973.

-Vizcarra, Ignacio S., Apuntes y datos cronologicos para la historia de Colima, Talleres Impresores Mexicanos, México, 1949. 